\title{
Metformin-induced glucagon-like peptide-1 secretion contributes to the actions of metformin in type 2 diabetes
}

\author{
Emilie Bahne, ${ }^{1}$ Emily W. L. Sun, ${ }^{2}$ Richard L. Young, ${ }^{3,4}$ Morten Hansen, ${ }^{1,5}$ David P. Sonne, ${ }^{1,6}$ \\ Jakob S. Hansen, ${ }^{1}$ Ulrich Rohde, ${ }^{1,5}$ Alice P. Liou, ${ }^{7}$ Margaret L. Jackson, ${ }^{7}$ Dayan de Fontgalland, ${ }^{8}$ \\ Philippa Rabbitt, ${ }^{8}$ Paul Hollington, ${ }^{8}$ Luigi Sposato, ${ }^{8}$ Steven Due, ${ }^{8}$ David A. Wattchow, ${ }^{8}$

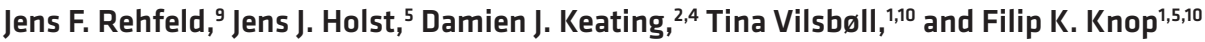 \\ ${ }^{1}$ Clinical Metabolic Physiology, Steno Diabetes Center Copenhagen, Gentofte Hospital, Hellerup, Denmark. ${ }^{2}$ Discipline of \\ Human Physiology and Centre for Neuroscience, Flinders University of South Australia, Adelaide, Australia. ${ }^{3}$ Adelaide \\ Medical School, University of Adelaide, Adelaide, Australia. ${ }^{4}$ Nutrition and Metabolism, South Australian Health \\ and Medical Research Institute (SAHMRI), Adelaide, Australia. ${ }^{5}$ Novo Nordisk Foundation Center for Basic Metabolic \\ Research, Faculty of Health and Medical Sciences, University Copenhagen, Copenhagen, Denmark. ${ }^{6}$ Department of Clinical \\ Pharmacology, Frederiksberg and Bispebjerg Hospital, University of Copenhagen, Denmark. ${ }^{7}$ Cardiovascular and Metabolic \\ Diseases Research Unit, Pfizer Worldwide Research and Development, Cambridge, Massachusetts, USA. ${ }^{8}$ Discipline of \\ Surgery, Flinders University, Adelaide, South Australia, Australia. ${ }^{9}$ Department of Clinical Biochemistry, Rigshospitalet, \\ University Copenhagen, Copenhagen, Denmark. ${ }^{10}$ Department of Clinical Medicine, Faculty of Health and Medical Sciences, \\ University Copenhagen, Copenhagen, Denmark.
}

BACKGROUND. Metformin reduces plasma glucose and has been shown to increase glucagon-like peptide 1 (GLP-1) secretion. Whether this is a direct action of metformin on GLP-1 release, and whether some of the glucose-lowering effect of metformin occurs due to GLP-1 release, is unknown. The current study investigated metformin-induced GLP-1 secretion and its contribution to the overall glucose-lowering effect of metformin and underlying mechanisms in patients with type 2 diabetes.

METHODS. Twelve patients with type 2 diabetes were included in this placebo-controlled double-blinded study. On 4 separate days, the patients received metformin $(1,500 \mathrm{mg}$ ) or placebo suspended in a liquid meal, with subsequent i.v. infusion of the CLP-1 receptor antagonist exendin9-39 (Ex9-39) or saline. During 240 minutes, blood was sampled. The direct effect of metformin on GLP-1 secretion was tested ex vivo in human ileal and colonic tissue with and without dorsomorphin-induced inhibiting of the AMPK activity.

RESULTS. Metformin increased postprandial GLP-1 secretion compared with placebo $(P=0.014)$, and the postprandial glucose excursions were significantly smaller after metformin + saline compared with metformin + Ex9-39 $(P=0.004)$. Ex vivo metformin acutely increased CLP-1 secretion (colonic tissue, $P<0.01$; ileal tissue, $P<0.05$ ), but the effect was abolished by inhibition of AMPK activity.

contributed equally to this work. DJK and FKK are co-senior authors.

Conflict of interest: Funding was received by RLY and DJK from Pfizer Inc. through an Emerging Science Grant. AL and M) were employees of Pfizer Inc. during this study.

License: Copyright 2018, American Society for Clinical Investigation.

Submitted: May 17, 2017

Accepted: October 24, 2018

Published: December 6, 2018

Reference information:

JCI Insight. 2018;3(23):e93936

https://doi.org/10.1172/jici.

insight.93936.

CONCLUSIONS. Metformin has a direct and AMPK-dependent effect on GLP-1-secreting L cells and increases postprandial CLP-1 secretion, which seems to contribute to metformin's glucose-lowering effect and mode of action.

TRIAL REGISTRATION. NCT02050074 (https://clinicaltrials.gov/ct2/show/NCT02050074).

FUNDING. This study received grants from the A.P. Møller Foundation, the Novo Nordisk Foundation, the Danish Medical Association research grant, the Australian Research Council, the National Health and Medical Research Council, and Pfizer Inc.

\section{Introduction}

For decades, metformin has been used in the treatment of type 2 diabetes, and it is currently recommended as the first-line treatment of type 2 diabetes. Despite wide use, its exact mechanisms of action are still a subject of ongoing investigation (1). It is known to decrease hepatic gluconeogenesis (2) and improve peripheral 
insulin sensitivity (3) through activation of AMPK in metabolically active organs, including the liver (4), skeletal muscles (5), and adipose tissue (6). A more recently appreciated mechanism of action of metformin is focused on the gastrointestinal tract $(1,7)$. This view is supported by the effect of metformin on hepatic glucose production with oral, but not parenteral, administration of the drug (1, 7-9). This is further supported by trials demonstrating that both extended and delayed-release formulations of metformin have more potent glucose-lowering effects in type 2 diabetes patients than immediate release formulations of equivalent doses, without increasing the incidence of adverse effects $(10,11)$. Interestingly, delayed-release formulation of metformin was shown to be superior in lowering fasting blood glucose levels over the extended-release formulation in a randomized controlled trial, further strengthening this association (12). Such data associates the prolonged exposure of the gastrointestinal tract to metformin with improved efficacy of the drug.

One mechanism underlying this potential gut-mediated glucose-lowering effect of metformin may be through the incretin axis. An increasing body of clinical evidence suggests that metformin treatment increases both fasting and postprandial levels of the glucose-lowering and satiety-promoting incretin hormone, glucagon-like peptide 1 (GLP-1) (11, 13-16). GLP-1 is secreted from enteroendocrine L cells, located throughout the intestines (in highest numbers in the ileum and colon; ref. 17), in response to nutrients and is rapidly inactivated by dipeptidyl peptidase 4 (DPP-4) (18). GLP-1 enhances glucose-induced insulin secretion and inhibits glucagon secretion. Moreover, GLP-1 delays gastric emptying and reduces appetite and food intake (18). The mechanisms underlying the increased plasma GLP-1 concentrations associated with metformin treatment are poorly understood. Rodent studies showed that acute metformin administration could trigger GLP-1 secretion, regardless of the feeding status of the animals $(14,19,20)$, and both preclinical $(19,21)$ and clinical studies $(14,20)$ suggest that metformin increases GLP-1 secretion rather than reducing GLP-1 degradation. However, evidence supporting a direct effect of metformin on human L cells is lacking. Interestingly, metformin has been suggested to inhibit the apical sodium-dependent bile acid transporter (ASBT) in the ileum, thereby increasing the luminal concentration of bile acids in the ileum and colon (22). Bile acids activate the nuclear farnesoid X receptor (FXR) $(23,24)$, as well as the membrane-associated G protein-coupled receptor, TGR5 $(25,26)$, and may be involved in the regulation of glucose metabolism $(27,28)$. Furthermore, exogenous bile acids increase circulating GLP-1 in animal and human studies (27, 29-31). Thus, metformin-induced GLP-1 secretion may arise indirectly through activation of bile acid receptors in the intestine.

In this study, we evaluated the effects of metformin-induced postprandial GLP-1 secretion on postprandial glucose metabolism in 12 patients with type 2 diabetes by subjecting them to liquid meal tests on 4 separate experimental days with single-dose metformin $(1,500 \mathrm{mg})$ or matching placebo and with i.v. infusion of the specific GLP-1 receptor antagonist exendin9-39 (Ex9-39) or saline. We also evaluated whether acute exposure of metformin can directly trigger GLP-1 secretion in human ex vivo ileal and colonic mucosal tissue.

\section{Results}

Study patients. Twelve patients with type 2 diabetes ( 8 females, age $60.7 \pm 8.8$ years (mean \pm SD); BMI, 29.8 $\pm 3.0 \mathrm{~kg} / \mathrm{m}^{2}$; glycosylated hemoglobin $\mathrm{A}_{1 \mathrm{c}}, 6.5 \pm 0.5 \%(47.5 \pm 6.0 \mathrm{mmol} / \mathrm{mol})$; fasting plasma glucose, 7.7 $\pm 1.0 \mathrm{mmol} / \mathrm{1}$; diabetes duration, $8.1 \pm 3.1$ years) were included in the study. The patients were all treated with diet in combination with metformin monotherapy $(n=11)$ or metformin plus gliclazide $(n=1)$. None of the patients suffered from diabetic complications. Twenty-one patients were screened. The data (time points 0-240 minutes) from the day of placebo + Ex9-39 from 1 patient are missing, as the patient vomited twice after ingestion of the liquid meal. These data points are excluded from the figures. In order to perform the 1-way repeated measures ANOVA and post hoc Tukey's multiple comparisons test, the missing values were extrapolated from the mean values of the other 11 patients, who completed the placebo + Ex9-39 day.

Metformin increases postprandial GLP-1 in patients with type 2 diabetes. Time courses of GLP-1 plasma concentrations and incremental AUCs (iAUCs) are illustrated in Figure 1A, and AUCs are given in Table 1. Basal GLP-1 concentrations did not differ between the days. The GLP-1 iAUC was significantly greater after metformin + saline vs. placebo + saline $(P=0.014)$. There was a tendency toward Ex9-39-induced GLP-1 secretion after metformin compared with saline $(P=0.08)$. GLP-1 iAUC was significantly greater after metformin + Ex939 vs. placebo + Ex9-39 $(P=0.026)$. Time courses and iAUCs of glucagon plasma concentrations are illustrated in Figure 1B, and AUCs are given in Table 2. On the 2 days with Ex9-39 infusion, mean basal concentrations of plasma glucagon were higher compared with the 2 days of saline infusion $(25.9 \pm 2.5 \mathrm{nmol} / 1 \mathrm{vs} .23 .6 \pm 2.1 \mathrm{nmo}-$ $1 / 1, P=0.018)$. Glucagon concentrations, expressed as iAUC, were increased by metformin + Ex9-39 compared with placebo + saline $(P=0.004)$. Glucagon concentrations increased after meal ingestion on all days. 

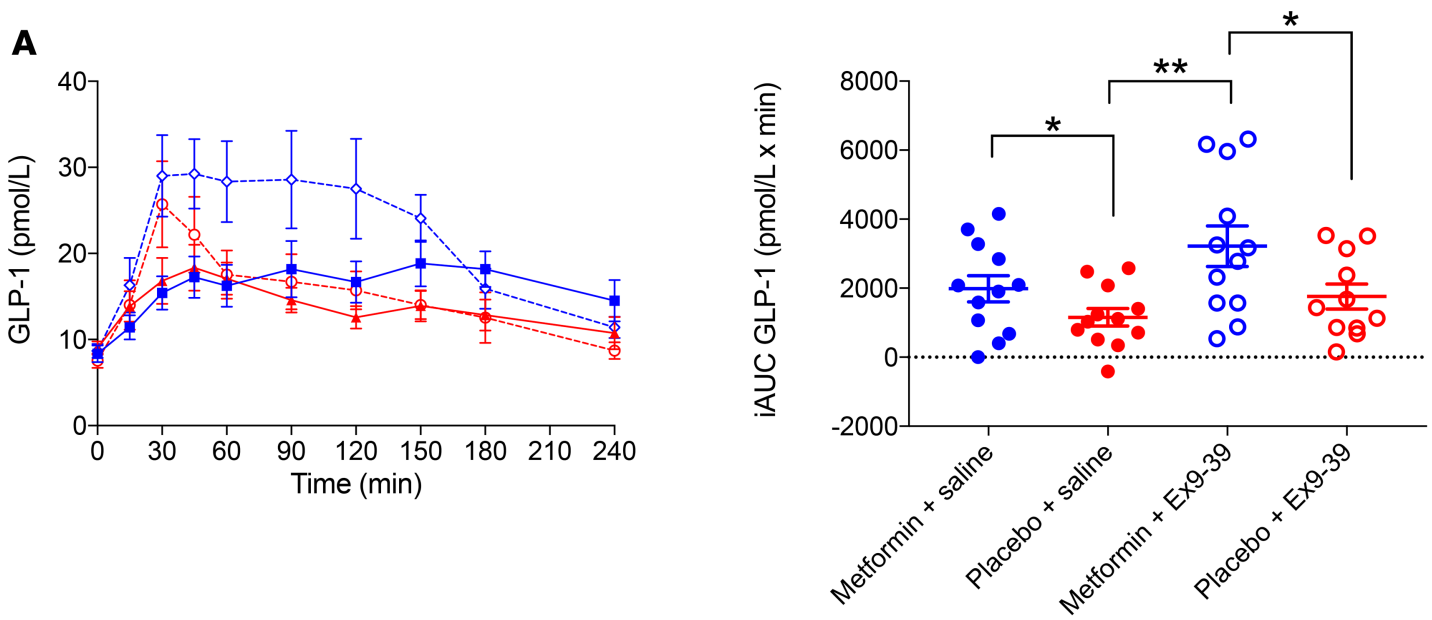

B

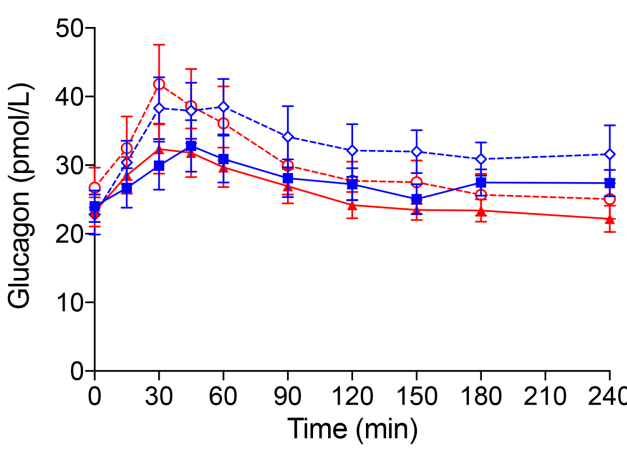

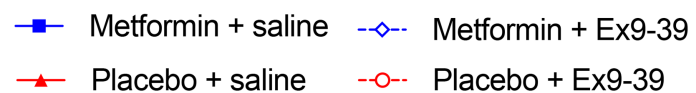

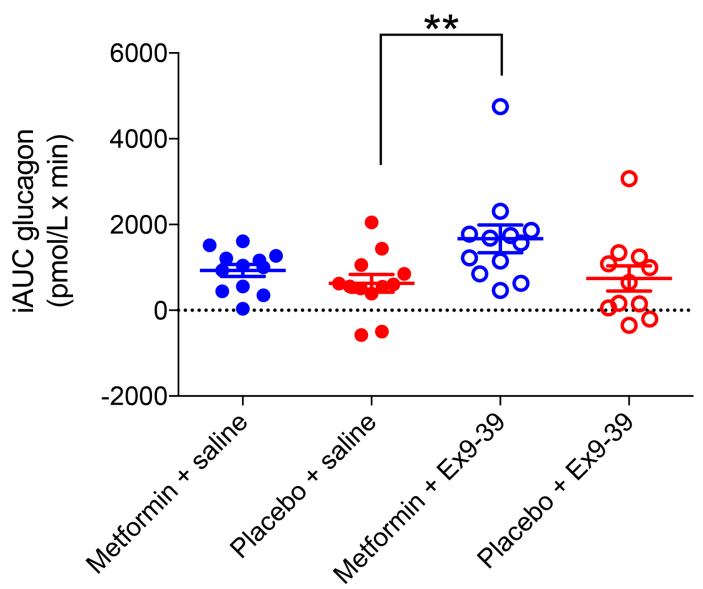

Figure 1. Time courses and incremental AUCs (iAUC) of postprandial plasma concentrations of glucagon-like peptide 1 (GLP-1) and glucagon. Time courses (0-240 minutes) and iAUCs of postprandial GLP-1 (A) and glucagon (B), after receiving a single dose of metformin (1,500 mg) or placebo with subsequent i.v. infusion of saline or exendin9-39 (Ex9-39), respectively, in 12 patients with type 2 diabetes. Data are means $\pm S E M$. ${ }^{*} P<0.05,{ }^{* *} P<0.01$. Comparisons performed by 1-way repeated measures ANOVA with Tukey's multiple comparison post hoc test.

Metformin reduces postprandial plasma glucose — partly via GLP-1 signaling. Mean Ex9-39 concentrations from time 0-240 minutes were similar between the metformin + Ex-9-39 and placebo + Ex9-39 days (305 $\pm 15 \mathrm{nmol} / 1$ vs. $301 \pm 17 \mathrm{nmol} / 1, P=0.723$ ) (Supplemental Figure 1; supplemental material available online with this article; https://doi.org/10.1172/jci.insight.93936DS1). Time courses of plasma glucose concentrations are illustrated in Figure 2A, and AUCs are given in Table 2. On the 2 days with Ex9-39 infusion, mean basal concentrations of plasma glucose were higher compared with the 2 days of saline infusion $(9.8 \pm 0.58 \mathrm{mmol} / 1 \mathrm{vs} .8 .7 \pm 0.52$ $\mathrm{mmol} / 1, P=0.003$ ). Therefore, we used iAUCs to evaluate the impact of metformin and Ex9-39 on postprandial glucose tolerance. The glucose iAUC after metformin + saline was significantly smaller than the iAUC for placebo + saline $(P=0.04)$, whereas the difference between metformin and placebo during GLP-1 receptor blockage did not reach statistical significance (metformin + Ex9-39 vs. placebo + Ex9-39, $P=0.053$ ). The glucose iAUC after metformin + saline was significantly smaller than the iAUC for metformin + Ex9-39 $(P=0.004)$. Based on individual iAUC values, the relative contribution of GLP-1 to the acute glucose-lowering effect of metformin was $75 \% \pm 35 \%$, calculated as follows: $100 \% \times\left(\left[\mathrm{iAUC}\right.\right.$ placebo + saline $\left.-\mathrm{iAUC}_{\text {metformin }+ \text { saline }}\right]-\left[\mathrm{iAUC}_{\text {placebo }+ \text { Ex } 9-39}-\right.$ $\left.\left.\mathrm{iAUC}_{\text {metformin + Ex9-39 }}\right]\right) /\left(\mathrm{iAUC}_{\text {placebo + saline }}-\mathrm{iAUC}_{\text {metformin }+ \text { saline }}\right)(P=0.05)$. Using a 2-way ANOVA, both metformin and Ex9-39 were shown to significantly affect postprandial plasma glucose (iAUC) $(P=0.005$ and $P=0.002$, respectively), but no interaction between the 2 factors was evident. The time courses of the $\mathrm{C}$-peptide/glucose ratios are illustrated in Figure 2B, and the AUCs for C-peptide/glucose, insulin/glucose, and insulin secretion 
Table 1. GLP-1, acetaminophen, total bile acids, and gallbladder volume

\begin{tabular}{|c|c|c|c|}
\hline GLP-1 & $\begin{array}{c}\text { Basal } \\
(\mathrm{pmol} / \mathrm{l})\end{array}$ & $\begin{array}{l}\text { AUC 0-240 min } \\
(\mathrm{nmol} / \mathrm{I} \times \mathrm{min})\end{array}$ & $\begin{array}{l}\text { iAUC 0-240 min } \\
\text { (nmol/I } \times \text { min) }\end{array}$ \\
\hline (1) MET + saline & $8 \pm 0.9$ & $3,951 \pm 473$ & $1,984 \pm 365^{A 2}$ \\
\hline (2) PLA + saline & $9 \pm 0.7$ & $3,303 \pm 348$ & $1,156 \pm 244^{A 3}$ \\
\hline (3) $M E T+E x 9-39$ & $9 \pm 0.8$ & $5,285 \pm 641^{A 2,4}$ & $3,218 \pm 563^{A 4}$ \\
\hline (4) PLA + Ex9-39 & $8 \pm 1.1$ & $3,594 \pm 432$ & $1,761 \pm 316$ \\
\hline Acetaminophen & $\begin{array}{c}\text { Basal } \\
(\mathrm{mmol} / \mathrm{l})\end{array}$ & $\begin{array}{l}\text { Tmax } \\
\text { (min) }\end{array}$ & $\begin{array}{l}\text { AUC 0-60 min } \\
(\mathrm{mmol} / \mathrm{I} \times \mathrm{min})\end{array}$ \\
\hline (1) MET + saline & $0.003 \pm 0.00$ & $91.3 \pm 6.2$ & $2.82 \pm 0.17^{A 3}$ \\
\hline (2) PLA + saline & $0.003 \pm 0.00$ & $85.0 \pm 4.8$ & $3.27 \pm 0.26$ \\
\hline (3) MET + Ex9-39 & $0.003 \pm 0.00$ & $85.0 \pm 6.9$ & $3.47 \pm 0.24$ \\
\hline (4) PLA + Ex9-39 & $0.005 \pm 0.00$ & $90.4 \pm 9.4$ & $3.47 \pm 0.34$ \\
\hline Total bile acids & $\begin{array}{c}\text { Basal } \\
(\mu \mathrm{mol} / \mathrm{l})\end{array}$ & $\begin{array}{l}\text { AUC 0-240 min } \\
(\mu \mathrm{mol} / / \times \mathrm{min})\end{array}$ & $\begin{array}{l}\text { iAUC 0-240 min } \\
(\mu \mathrm{mol} / / \mathrm{L} \times \mathrm{min})\end{array}$ \\
\hline (1) MET + saline & $2.1 \pm 0.7$ & $1,850 \pm 469$ & $1,352 \pm 365$ \\
\hline (2) PLA + saline & $1.4 \pm 0.3$ & $1,566 \pm 284$ & $1,228 \pm 260$ \\
\hline (3) $M E T+E x 9-39$ & $1.5 \pm 0.3$ & $1,887 \pm 210$ & $1,518 \pm 201$ \\
\hline (4) PLA + Ex9-39 & $1.5 \pm 0.5$ & $1,386 \pm 284$ & $1,030 \pm 253$ \\
\hline Gallbladder volume & $\begin{array}{l}\text { Basal } \\
(\mathrm{ml})\end{array}$ & $\begin{array}{l}\text { AUC 0-240 min } \\
(\mathrm{ml} \times \mathrm{min})\end{array}$ & $\begin{array}{l}\text { AUC 60-240 min } \\
(\mathrm{ml} \times \mathrm{min})\end{array}$ \\
\hline (1) MET + saline & $27.0 \pm 2.5$ & $4,902 \pm 573$ & $3,960 \pm 462$ \\
\hline (2) PLA + saline & $28.0 \pm 4.2$ & $5,361 \pm 617$ & $4,402 \pm 490$ \\
\hline (3) $M E T+E x 9-39$ & $27.8 \pm 3.4$ & $5,416 \pm 752$ & $4,431 \pm 577$ \\
\hline (4) PLA + Ex9-39 & $25.5 \pm 2.9$ & $5,697 \pm 649$ & $4,821 \pm 596$ \\
\hline
\end{tabular}

Plasma glucagon-like peptide 1 (GLP-1), serum acetaminophen, total bile acids, and gallbladder volume after metformin + saline (MET + saline), placebo + saline (PLA + saline), metformin + exendin9-39 (MET + Ex9-39), and placebo + exendin9-39 (PLA + Ex9-39) in patients with type 2 diabetes. Data are means \pm SEM. iAUC, incremental AUC; Tmax, time to peak. Statistically significant differences between interventions by 1-way repeated measures ANOVA with Tukey's multiple comparison post hoc test is marked by ${ }^{A}$ followed by the number of the intervention compared with. $P<0.05$ was considered statistically significant, $n=12$.

rate (ISR)/glucose ratios are given in Table 2. Mean basal insulin/glucose ratio, C-peptide/glucose, and ISR/ glucose ratio were lower on the 2 days of Ex9-39 infusion vs. the 2 days of saline infusion $(8.3 \mathrm{pmol} / \mathrm{mmol} \pm$ 1.2 vs. $12.4 \mathrm{pmol} / \mathrm{mmol} \pm 1.7,73.5 \mathrm{pmol} / \mathrm{mmol} \pm 8.4 \mathrm{vs} .93 .7 \mathrm{pmol} / \mathrm{mmol} \pm 10.1$, and $0.3 \pm 0.0 \mathrm{vs} .0 .2 \pm 0.1$, respectively). Postprandial values of insulin/glucose ratio did not differ between the interventions (Supplemental Figure 2), but C-peptide/glucose and ISR/glucose ratios were higher after metformin + saline compared with placebo + saline $(P=0.004$ and $P=0.005$, respectively $)$, and placebo $+\operatorname{Ex} 9-39(P=0.008$ and $P<0.001$, respectively). The ISR/glucose ratios were also higher after metformin + saline compared with metformin + Ex9-39 ( $P$ $=0.040)$, and the same tendency was seen regarding the effect on $C$-peptide/glucose ratio $(P=0.051)$. Indices of gastric emptying are given in Table 1 . Metformin + saline significantly reduced gastric acetaminophen total AUC (tAUC $\left.{ }_{0-60 \text { min }}\right)$ compared with metformin + Ex9-39 $(P=0.04)$, indicating accelerated gastric emptying induced by Ex9-39. There was no difference between metformin and placebo on either $\mathrm{AUC}_{0-60 \mathrm{~min}}$ or time to maximal plasma concentration $\left(T_{\max }\right)$. (Supplemental Figure 3). None of the interventions affected appetite perceptions, thirst (Supplemental Figure 4), or ad libitum food intake significantly (Supplemental Figure 5).

Metformin and Ex9-39 have no effect on postprandial plasma cholecystokinin (CCK), gallbladder motility, or total serum bile acids. On all 4 days, CCK concentrations increased immediately after ingestion of the liquid meal, but no differences in the responses were observed (Supplemental Figure 6). Indices of gallbladder motility are given in Table 1 . Baseline gallbladder volume and gallbladder contraction between 0-60 minutes were similar between the days. The refilling of the gallbladder from $60-240$ minutes was similar after metformin + saline vs. placebo + saline. The gallbladder refilling was also similar after Ex939 with either metformin or placebo (Supplemental Figure 7). AUCs of total serum bile acids are given in Table 1. Basal concentrations of total bile acids did not differ between the 4 study days. On all 4 days after ingestion of the liquid meal, serum bile acids increased rapidly and peaked after 45-60 minutes. 
Table 2. Glucose, insulin, C-peptide, ISR, and glucagon

\begin{tabular}{|c|c|c|c|}
\hline Glucose & $\begin{array}{c}\text { Basal } \\
(\mathrm{mmol} / \mathrm{l})\end{array}$ & $\begin{array}{l}\text { AUC 0-240 min } \\
(\mathrm{pmol} / \mathrm{I} \times \mathrm{min})\end{array}$ & $\begin{array}{l}\text { iAUC 0-240 min } \\
(\mathrm{pmol} / / \times \mathrm{min})\end{array}$ \\
\hline (1) MET + saline & $9.2 \pm 0.8$ & $2,349 \pm 246$ & $145 \pm 68^{A 2,3,4}$ \\
\hline (2) PLA + saline & $8.3 \pm 0.6$ & $2,340 \pm 191$ & $350 \pm 73^{\mathrm{A4}}$ \\
\hline (3) $M E T+E \times 9-39$ & $10.0 \pm 0.9$ & $2,856 \pm 315$ & $467 \pm 112$ \\
\hline (4) $P L A+E \times 9-39$ & $9.6 \pm 0.7$ & $2,933 \pm 278$ & $623 \pm 119$ \\
\hline Insulin/glucose ratio & $\begin{array}{c}\text { Basal } \\
(\mathrm{nmol} / \mathrm{mol})\end{array}$ & $\begin{array}{l}\text { AUC 0-240 min } \\
(\mathrm{nmol} / \mathrm{mol} \times \mathrm{min})\end{array}$ & $\begin{array}{l}\text { iAUC 0-240 min } \\
(\mathrm{nmol} / \mathrm{mol} \times \mathrm{min})\end{array}$ \\
\hline (1) MET + saline & $0.01 \pm 0.00$ & $6.6 \pm 1.1$ & $3.8 \pm 0.8$ \\
\hline (2) PLA + saline & $0.01 \pm 0.00$ & $6.2 \pm 1.1$ & $3.1 \pm 0.7$ \\
\hline (3) MET + Ex9-39 & $0.01 \pm 0.00$ & $5.5 \pm 1.1$ & $3.5 \pm 0.9$ \\
\hline (4) $P L A+E \times 9-39$ & $0.01 \pm 0.00$ & $5.5 \pm 1.0$ & $3.4 \pm 0.8$ \\
\hline C-peptide/glucose ratio & $\begin{array}{c}\text { Basal } \\
\text { (nmol/mol) }\end{array}$ & $\begin{array}{l}\text { AUC 0-240 min } \\
(\mathrm{nmol} / \mathrm{mol} \times \mathrm{min})\end{array}$ & $\begin{array}{l}\text { iAUC 0-240 min } \\
(\mathrm{nmol} / \mathrm{mol} \times \mathrm{min})\end{array}$ \\
\hline (1) MET + saline & $0.09 \pm 0.01$ & $40.3 \pm 5.0$ & $18.2 \pm 2.7^{\mathrm{A2}, 4}$ \\
\hline (2) PLA + saline & $0.10 \pm 64.9$ & $35.2 \pm 3.7$ & $12.3 \pm 1.8$ \\
\hline (3) $M E T+E \times 9-39$ & $0.07 \pm 53.6$ & $30.0 \pm 4.7$ & $13.2 \pm 3.2$ \\
\hline (4) PLA + Ex9-39 & $0.08 \pm 70.2$ & $29.5 \pm 3.9$ & $11.2 \pm 3.1$ \\
\hline ISR/glucose ratio & $\begin{array}{c}\text { Basal } \\
(\mathrm{pmol} / \mathrm{l} / \mathrm{kg} / \mathrm{min} / \mathrm{mmol})\end{array}$ & $\begin{array}{c}\text { AUC } 0-240 \mathrm{~min} \\
(\mathrm{pmol} / \mathrm{l} / \mathrm{kg} / \mathrm{min} / \mathrm{mmol} \times \mathrm{min})\end{array}$ & $\begin{array}{c}\text { iAUC 0-240 min } \\
(\mathrm{pmol} / \mathrm{l} / \mathrm{kg} / \mathrm{min} / \mathrm{mmol} \times \mathrm{min})\end{array}$ \\
\hline (1) MET + saline & $0.3 \pm 0.0$ & $124.2 \pm 14.4$ & $59.5 \pm 8.0 \mathrm{~A}^{2,3,4}$ \\
\hline (2) PLA + saline & $0.3 \pm 0.0$ & $110.7 \pm 11.1$ & $43.9 \pm 6.0$ \\
\hline (3) MET + Ex9-39 & $0.2 \pm 0.0$ & $91.5 \pm 14.0$ & $40.9 \pm 9.2$ \\
\hline (4) PLA + Ex9-39 & $0.2 \pm 0.0$ & $93.3 \pm 13,1$ & $36.4 \pm 8.4$ \\
\hline Clucagon & $\begin{array}{c}\text { Basal } \\
(\mathrm{pmol} / \mathrm{l})\end{array}$ & $\begin{array}{l}\text { AUC 0-240 min } \\
(\mathrm{pmol} / \mathrm{I} \times \mathrm{min})\end{array}$ & $\begin{array}{l}\text { iAUC 0-240 min } \\
(\mathrm{pmol} / \mathrm{I} \times \mathrm{min})\end{array}$ \\
\hline (1) MET + saline & $24 \pm 2.2$ & $6,687 \pm 544$ & $928 \pm 134$ \\
\hline (2) PLA + saline & $23 \pm 2.0$ & $6,186 \pm 1,686$ & $628 \pm 199^{\text {A3 }}$ \\
\hline (3) MET + Ex9-39 & $26 \pm 2.5$ & $7,950 \pm 792$ & $1,668 \pm 308$ \\
\hline (4) PLA + Ex9-39 & $26 \pm 2.5$ & $7,150 \pm 767$ & $1,019 \pm 306$ \\
\hline
\end{tabular}

Plasma glucose, insulin/glucose ratio, C-peptide/glucose ratio, insulin secretion rate (ISR)/glucose ratio, and glucagon after metformin + saline (MET + saline), placebo + saline (PLA + saline), metformin + exendin9-39 (MET + Ex9-39), and placebo + exendin9-39 (PLA + Ex9-39) in patients with type 2 diabetes. Data are means \pm SEM. iAUC, incremental AUC. Statistically significant differences between interventions by 1-way repeated measures ANOVA with Tukey's multiple comparison post hoc test is marked by ${ }^{A}$ followed by the number of the intervention compared with. $P<0.05$ was considered statistically significant, $n=12$.

The iAUC for total bile acids did not differ after metformin + saline vs. placebo + saline $(P=0.87)$ and did not appear to be affected by Ex9-39 (Supplemental Figure 8).

Metformin triggers GLP-1 secretion in ex vivo human ileal and colonic mucosae. To understand how metformin causes GLP-1 release, we utilized an ex vivo secretion approach using human gut epithelial tissue sections. Exposure to high external $\mathrm{K}^{+}(70 \mathrm{mM})$ or to a combination of known activators of $\mathrm{L}$ cell secretion forskolin (FSK, $10 \mu \mathrm{M}$ ) and 3-isobutyl-1-methylxanthine (IBMX, $10 \mu \mathrm{M}$ ) both increased intact GLP-1 release from colonic epithelial tissue $(n=22, P<0.001$, Figure $3 \mathrm{~A})$. Acute exposure to metformin $(10 \mu \mathrm{M})$ also triggered an increase in intact GLP-1 levels ( $n=46, P<0.01$, Figure 3B). We saw a similar increase in GLP-1 release in response to metformin in ileal tissue $(n=10, P<0.05$, Figure $3 \mathrm{C})$. Thus, exposure of metformin increases GLP-1 release within 15 minutes from human colonic and ileal L cells. To identify whether the effect of metformin on $\mathrm{L}$ cell secretion was altered in human obesity or type 2 diabetes, we examined responses to metformin in our colonic preparation across BMI and in samples obtained from patients with type 2 diabetes. Neither the basal release of GLP-1, nor the degree of metformin-stimulated GLP-1 release, correlated with BMI ( $n=46$, Supplemental Figure 9). No difference was seen in either basal or stimulated GLP-1 release between tissue obtained from nondiabetes $(n=35)$ or type 2 diabetes individuals $(n=11$, Supplemental Figure 9). Thus, basal L cell secretion, and the response of L cells to metformin, do not seem to change across BMI and appear unrelated to diabetes status. We investigated the mechanism by which 
A

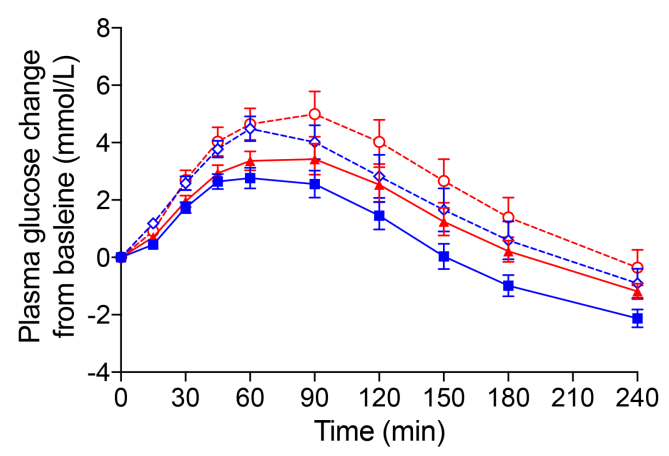

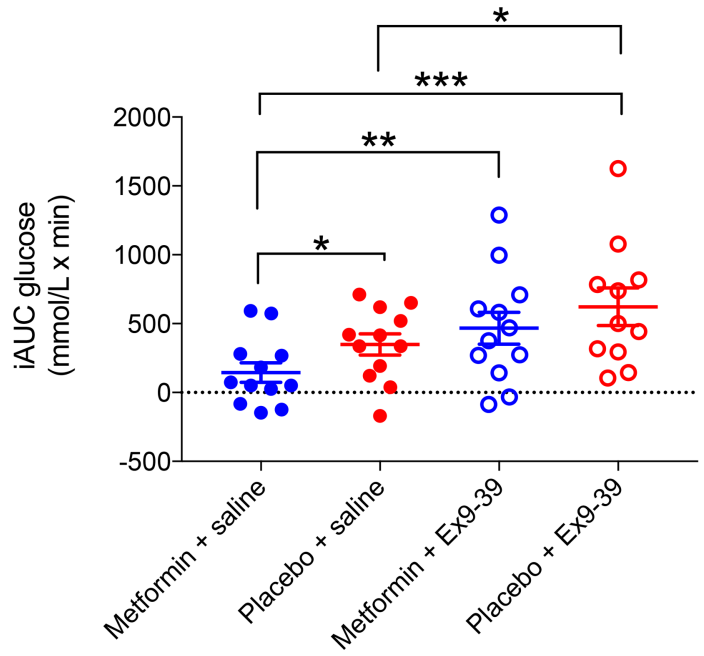

\section{B}

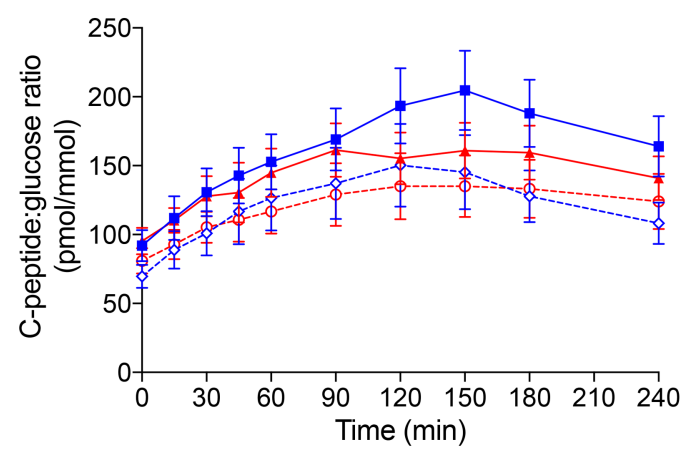

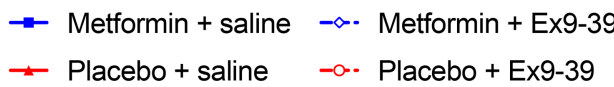

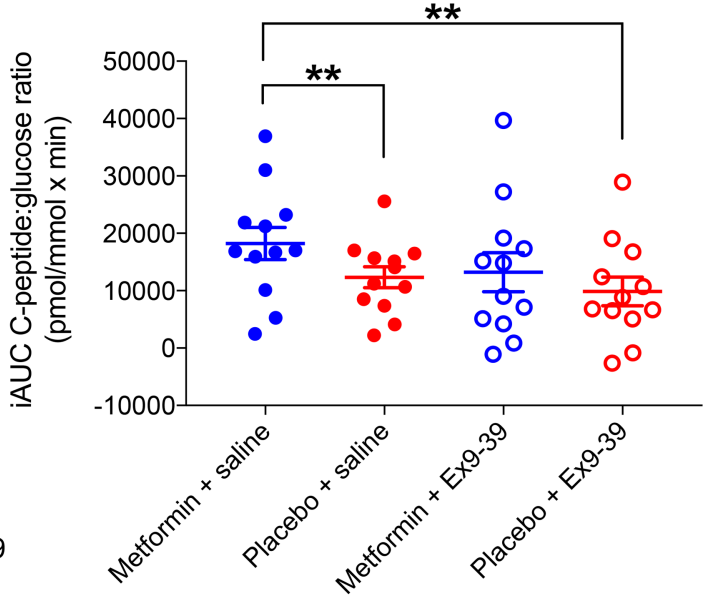

Figure 2. Time courses and incremental AUCs (iAUC) of postprandial plasma concentrations of glucose and the C-peptide/glucose ratio. Time courses (0-240 minutes) and iAUCs of postprandial glucose (A) and C-peptide/glucose ratio (B), after receiving a single dose of metformin (1,500 mg) or placebo with subsequent i.v. infusion of saline or exendin9-39 (Ex9-39), respectively, in 12 patients with type 2 diabetes. Data are means \pm SEM. ${ }^{*} P<0.05$,

${ }^{* *} P<0.01,{ }^{* * *} P<0.001$. Comparisons performed by 1-way repeated measures ANOVA with Tukey's multiple comparison post hoc test.

metformin triggers L cell secretion. AMPK has been associated with metformin action (4), and inhibiting AMPK activity using $10 \mu \mathrm{M}$ dorsomorphin blocked metformin-induced GLP-1 secretion ( $n=20$, Figure 3D). We then used a series of membrane transporter antagonists to identify the mechanism of metformin internalization in human colonic L cells. Quinine (organic cation transporter 1 [OCT1] inhibitor, $1 \mathrm{mM}$ ) and lopinavir (plasma membrane monoamine transporter [PMAT] inhibitor, $10 \mu \mathrm{M}$ ) had no effect on metformin-induced GLP-1 release, while fluoxetine (serotonin transporter [SERT] inhibitor, $1 \mu \mathrm{M}$ ) blocked metformin-induced GLP-1 release ( $n=18$, Figure $3 \mathrm{E}$ ).

\section{Discussion}

Here, we show that acute oral administration of metformin $(1,500 \mathrm{mg})$ reduces postprandial glucose excursion and increases postprandial plasma GLP-1 and C-peptide/glucose ratios in patients with type 2 diabetes. Ex9-39 reduced the effect of metformin on postprandial glucose excursions and ISR/glucose ratios, suggesting that the metformin-induced secretion of GLP-1 may play a role in the glucose-lowering effect of metformin. Furthermore, we demonstrate that metformin can directly cause release of GLP-1 from human gut epithelial tissue of nondiabetic individuals, as well as patients with type 2 diabetes.

In the clinical part of the present investigation, baseline plasma glucose and postprandial plasma glucose excursions were higher after Ex9-39 infusions, which confirms the role of GLP-1 as a major determinant 
A

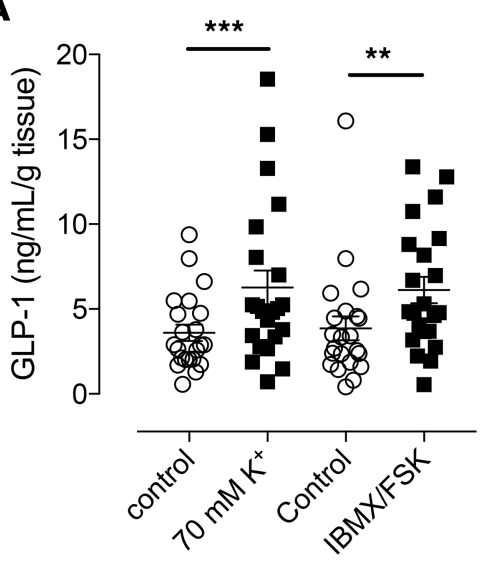

D

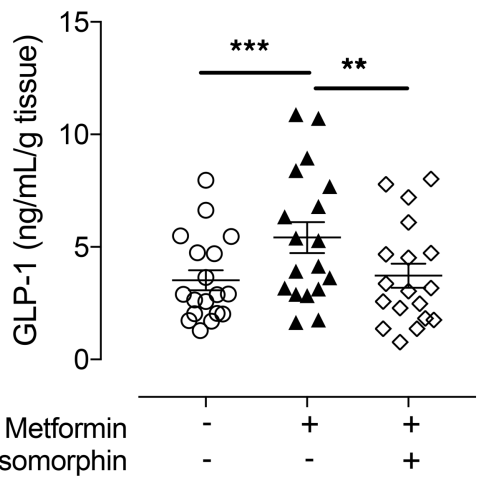

B

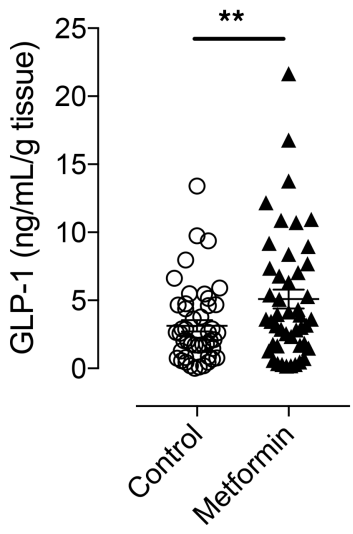

C

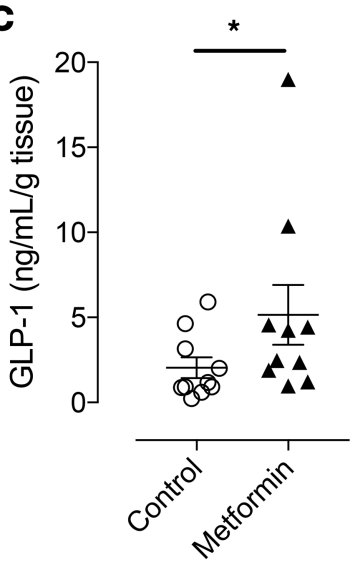

E

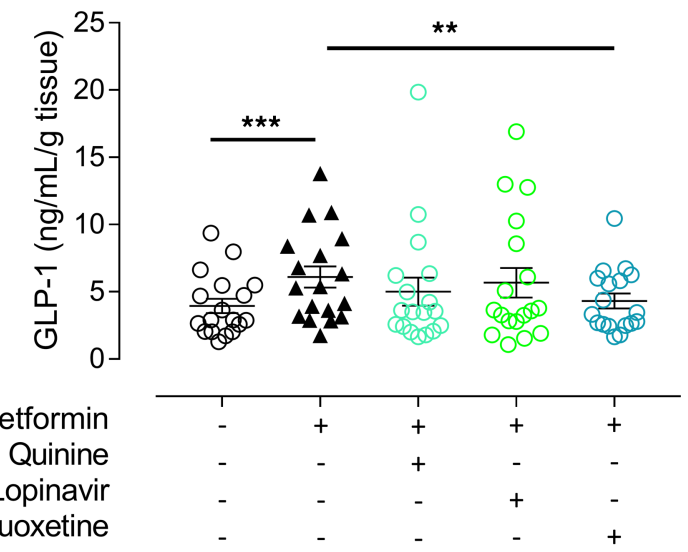

Figure 3. Metformin-induced secretion in human L cells. (A) Colonic epithelial preparations readily secrete glucagon-like peptide 1 (CLP-1) in response to high $(70 \mathrm{mM})$ external $\mathrm{K}^{+}$or to a combination of 3-isobutyl-1-methylxanthine (IBMX) and forskolin (FSK) $(n=22)$. (B and C) Metformin (10 $\mu$ M) increases CLP-1 release after 15 minutes in epithelial tissue from human colon $(n=46)$ (B) and ileum $(n=10)$ (C). (D) Metformin-induced GLP-1 release is blocked by the AMP-activated protein kinase (AMPK) inhibitor dorsomorphin $(n=18)$. (E) Metformin-induced GLP-1 release is blocked by the serotonin transporter (SERT) inhibitor fluoxetine and the plasma membrane monoamine transporter (PMAT) lopinavir $(n=18)$. Bar graph data are means \pm SEM. ${ }^{*} P<0.05$, ${ }^{* *} P<0.01,{ }^{* *} P<0.001$ compared with respective control groups. Comparisons performed by paired 1-way ANOVA and paired Student's $t$ test.

of glucose metabolism. We also observed smaller plasma glucose iAUCs after metformin compared with placebo, suggesting an acute effect of metformin on postprandial plasma glucose. Furthermore, the numerical difference in postprandial plasma glucose between metformin and placebo was reduced after Ex9-39 infusion, and when the relative impact of GLP-1 signaling on metformin-induced glucose-lowering was evaluated, it turned out that $75 \%$ could be attributed to GLP-1 signaling, underlining that a substantial part of metformin's acute glucose-lowering effect is probably mediated by the metformin-induced GLP-1 action. It should, however, be considered that our 2-way ANOVA showed a significant effect of both metformin and Ex9-39 on postprandial glucose excursions - but without interaction between the 2 factors. The latter result suggests that metformin's effect on postprandial glucose excursions is independent of Ex9-39 and calls for a cautious interpretation of our glucose results.

During test days with metformin, a tendency toward increased GLP-1 response was seen after Ex9-39 administration compared with saline, which is in line with previously reported data (32). This pattern is likely due to a feedback mechanism acting at the level of the $\mathrm{L}$ cell (33), which seems to work in a bidirectional fashion as increased GLP-1 signaling (e.g., from DPP-4 inhibition or i.v. administration of GLP-1) has been shown to decrease GLP-1 secretion from L cells $(33,34)$.

In the present study, postprandial GLP-1 secretion increased acutely after single-dose metformin (1,500 $\mathrm{mg}$ ) vs. placebo. This contrasts with a previous study by Mannucci et al. in which no acute effect of single-dose metformin $(850 \mathrm{mg})$ on GLP-1 secretion after an oral glucose load was observed (13). This discrepancy could 


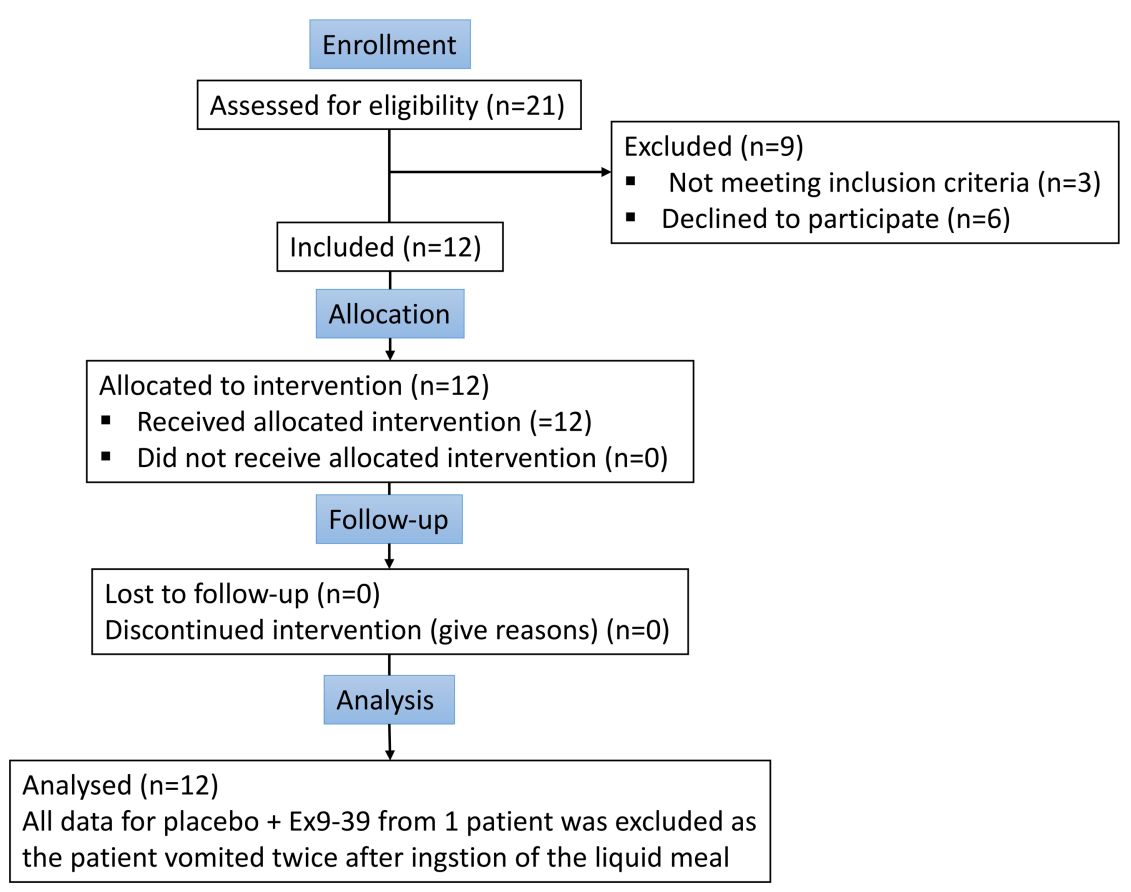

Figure 4. CONSORT diagram of the clinical study. The flow chart shows the number of patients who were screened, allocated to treatment, completed the study, and included in the final analysis. Ex9-39, exendin9-39.

be explained, perhaps by the lower dose of metformin. Another likely explanation to the lack of metformininduced potentiation of GLP-1 secretion in the Mannucci et al. study relates to their use of a pure glucose $(100 \mathrm{~g})$ stimulus vs. the mixed meal (containing $36.8 \mathrm{~g}$ carbohydrates, $12.0 \mathrm{~g}$ protein, and $11.6 \mathrm{~g}$ fat) used in the present study. As aforementioned, and previously reviewed (35), part of metformin's GLP-1-stimulating effect can be thought to be relayed by metformin-mediated reduction of bile acid reabsorption from the small intestines and ensuing increases in the concentration of intraluminal bile acids (36). Using a pure glucose stimulus will result in no or very small amounts of bile acids in the intestinal lumen for metformin to act on.

A previous report in L cell lines failed to show that metformin stimulates GLP-1 secretion, suggesting that the effect of metformin is indirect (19). Others have previously shown that chronic oral metformin treatment increases fasting and postprandial plasma GLP-1 levels in humans (11, 16, 37-39). However, these studies could not exclude the potential effects of metformin administration on the autonomic and enteric nervous systems or blood borne factors that influence GLP-1 secretion and actions, such as DPP-4 and bile acids. Our ex vivo study in human gut mucosae, however, showed that metformin is a direct secretagogue for the release of GLP-1 from L cells. Our data also indicate that internalization of metformin and downstream AMPK activation is required for this stimulatory effect. Metformin is known to activate AMPK in the liver (4), skeletal muscles (5), and adipose tissue (6), all of which contribute to its glucose-lowering effect. This is also consistent with acute AMPK activation being sufficient to cause GLP-1 release in vivo in rats (19). Based on the current knowledge of the membrane transporters involved in intestinal uptake of metformin (40) and that genetic variations in OCT1 $(41,42)$ and SERT $(43)$ are associated with variations in therapeutic response and gastrointestinal adverse reactions to the drug, we also hypothesized that metformin's stimulatory effect depends on active transport of the drug into the cell. In line with our hypothesis, we observed the attenuation of the stimulatory effect of metformin by pretreatment with the SERT inhibitor fluoxetine. While we hypothesize that metformin is transported into L cells via this transporter to enable AMPK activation and GLP-1 secretion, we cannot discount the possibility of an indirect effect of metformin activating serotonin release from local enterochromaffin cells $(44,45)$ and transportation of 5-HT into L cells activating release. This seems less likely, however, given that the major signaling pathways of serotonin involve binding to and activation of plasma membrane serotonin receptors.

The oral bioavailability of metformin is approximately $50 \%$, with an estimated $30 \%$ of an ingested dose recoverable in feces (46). This incomplete absorption of metformin means that the lower intestine, the body's richest source of GLP-1, is exposed to a considerable portion of an oral dose. Considering the 
importance of GLP-1 in maintaining energy homeostasis $(18,47)$, results from our study could serve to explain why delayed-release formulations of metformin have a more potent glucose-lowering effect than immediate and extended-release formulations of equivalent doses, albeit achieving lower plasma concentrations of metformin when compared with these formulations $(11,12)$. Since higher plasma metformin levels are associated with increased incidence of lactic acidosis, a rare but severe adverse drug reaction associated with metformin use (11), the use of delayed-release formulations can therefore minimize systemic exposure to metformin but maintain a comparable, if not superior, glucose-lowering effect. In addition, we did not observe any differences in metformin-induced GLP-1 release between nondiabetic controls and type 2 diabetes patients, and no relationship was evident between release and BMI, indicating that the potency of metformin to trigger GLP-1 release is preserved in obese patients and in patients with type 2 diabetes. Given the preserved insulinotropic and glucagonostatic effects of GLP-1 in type 2 diabetes patients (48-50), our results provide additional mechanistic explanation for the efficacy of metformin in lowering blood glucose levels in type 2 diabetes patients.

The higher plasma glucose concentrations on the days of Ex9-39 infusions represents a strong stimulus for insulin secretion and, as such, may blunt the Ex9-39-mediated inhibition of the insulinotropic effect of GLP-1 (51). To account for the varying glucose levels, insulin, C-peptide, and ISR were expressed as ratios to plasma glucose expressing the $\beta$ cell sensitivity to glucose. Basal insulin/glucose, C-peptide/glucose, and ISR/glucose ratios were lower on the 2 days of Ex9-39 infusion vs. the 2 days of saline infusion, which underlines the role of GLP-1 on human glucose even in the fasting state. The higher C-peptide/glucose and ISR/glucose ratios after metformin + saline compared with placebo + saline suggest an acute postprandial effect of metformin on insulin secretion, which may be mediated by the metformin-induced GLP-1 secretion.

Basal glucagon concentrations were higher on the days of Ex9-39 infusions compared with saline. This correlates well with the same pattern for the basal plasma glucose concentrations. Interestingly, we observed metformin-induced glucagon secretion when GLP-1 signaling was blocked by Ex9-39. This may illustrate the glucagonostatic effect of GLP-1, which has been shown to play an important role for the glucose-lowering properties of GLP-1 (52). A similar pattern has been observed in WT mice, where metformin increased plasma glucagon, compared with vehicle and in GLP-1 receptor-KO mice, where the effect was pronounced (14). Thus, it appears that the reduced hepatic glucose production associated with metformin treatment (53) occurs despite increased plasma glucagon concentrations. In line with this, Miller et al. suggested that metformin suppresses hepatic glucose production by inhibiting glucagon signaling pathways in the hepatocytes (2). One could speculate that this results in inhibition of a negative feedback loop, leading to increased glucagon secretion from the pancreatic $\alpha$ cell, which could explain the increase in plasma glucagon observed in the study. This would be in agreement with data from glucagon receptorKO mice, which exhibit increased plasma glucagon concentrations and $\alpha$ cell hyperplasia (54). Finally, it is possible that metformin increases gut-derived glucagon secretion (55).

Gastric emptying assessed as acetaminophen AUC $_{0-60 \text { min }}$ was accelerated when GLP-1 signaling was blocked by Ex9-39 during metformin treatment. This difference was not found when blocking GLP-1 signaling during placebo treatment, which could suggest that the effect of metformin on gastric emptying is mediated by GLP-1. It is well-established that i.v. infusion of GLP-1 dose-dependently inhibits gastric emptying (56), but whether GLP-1 secreted from the L cell has physiological importance for postprandial inhibition of gastric emptying is controversial. Nicolaus et al. showed that gastric emptying of a mixed semisolid meal was not affected by Ex9-39 in healthy subjects (51). This is in contrast to the findings of Deane et al., who reported that Ex9-39 accelerated gastric emptying of a semisolid mixed meal in healthy subjects (57). One explanation behind the lack of effect of Ex9-39 on gastric emptying in the present study, may be the higher plasma glucose concentration (on the days of Ex9-39), which has been shown to dose-dependently reduce gastric emptying (58).

As discussed above, GLP-1 decelerates gastric emptying and intestinal motility in general (18), and Ex9-39 might therefore be expected to increase gallbladder emptying. Furthermore, hyperglycemia (as observed during Ex9-39 infusion) dose-dependently inhibits postprandial gallbladder contractility (59). However, Ex9-39 did not affect fasting gallbladder volume or postprandial gallbladder contraction in this study. This is in contrast to the effect of acute administration of the GLP-1 receptor agonist exenatide, which has been demonstrated to impair CCK-induced gallbladder emptying (60). This may be interpreted as a pharmacological effect of the GLP-1 receptor agonist rather than a physiological effect of GLP-1. 
Importantly, gallbladder emptying should be interpreted with any effect of gastric emptying in mind, as a reduction in gastric emptying would also reduce gallbladder emptying (61).

Total serum bile acids after acute metformin administration was not significantly different from placebo. A recent study showed that serum bile acids increased after withdrawal of stable dose metformin (39). Furthermore, it has previously been reported that metformin inhibits bile acid reabsorption in the ileum (22). However, acute administration of metformin and the relative short duration of the present experiments may explain the discrepancy between the findings. The effect of metformin on total bile acids was unaffected by Ex9-39.

Metformin did not affect appetite perceptions, thirst, or food intake. Moreover, GLP-1 receptor antagonism with Ex9-39 did not affect appetite perceptions or food intake, which is line with previously published data from healthy subjects (62). There may be several reasons why Ex9-39 does not increase appetite and food intake. First, satiety physiology is highly complex, including postprandial endocrine inputs from a multitude of gut hormones. For example, the satiety hormones CCK and PYY may be upregulated, when GLP-1 signaling is antagonized (63). Furthermore, the observed increase in glucagon concentrations following Ex9-39 infusion may lead to decreased appetite and food intake (63).

A potential limitation of our study is that even the small differences in gastric emptying make it difficult to interpret differences in gut hormone secretion and gallbladder emptying. On the other hand, our design with oral administration of metformin with a meal offers a clinically relevant setting. In addition, the study assessed the acute effect of metformin, and it is possible that chronic treatment with metformin may have more pronounced effects on GLP-1 secretion as previously suggested (15). Certainly, our ex vivo data illustrate the ability of metformin to directly induce $\mathrm{L}$ cell secretion, but such an effect will be modified in vivo due to reduced dosage upon reaching the ileum and colon and by the potential for other factors to affect this response. Finally, a residual effect of GLP-1 may persist due to the submaximal GLP-1 receptor antagonism ( 90\%) at the chosen Ex9-39 dose, which could potentially underestimate the effect of metformin-induced GLP-1 secretion (64).

In conclusion, we show that, in patients with type 2 diabetes, metformin acutely increases postprandial GLP-1 secretion and reduces postprandial glucose excursion, as assessed by plasma glucose iAUC. We further demonstrate that such an effect can occur through the direct activation of L cell secretion via AMPK activation. The reduction in plasma glucose concentrations after metformin was significantly reduced by Ex9-39, and based on individual glucose excursion data, we calculated the contribution of metformin-induced GLP-1 secretion to the overall glucose-lowering effect of metformin to amount to $75 \%$. However, a 2-way ANOVA showed no interaction between metformin and Ex9-39 when evaluating postprandial glucose excursions. Nevertheless, Ex9-39 abolished the effects of metformin on ISR/glucose ratios and tended to have the same effect on the C-peptide/glucose ratio. Taken together, our findings indicate that part of the acute glucose-lowering effect of metformin is mediated by increased GLP-1 secretion, although studies with longer treatment duration or clamped blood glucose levels are needed to establish the precise role of GLP-1 in metformin's glucose-lowering effects.

\section{Methods}

Clinical study design. The clinical study was a randomized, double-blinded, placebo-controlled study. Screening visits and all experiments were conducted at Center for Diabetes Research at Gentofte Hospital. A flowchart is provided to report the flow of participants through the study and to indicate participants who were included or excluded from the final analysis (Figure 4). The patients were randomized to a random intervention sequence (using www.random.org) by an unblinded colleague at Center for Diabetes Research, and liquid meals and i.v. infusions (see below) were prepared by laboratory technicians. The principal investigator $(\mathrm{MH})$ remained blinded for the sequence of the study procedures. Power calculations were based on minimal relevant change in postprandial plasma GLP-1 concentrations assessed as AUC. Other endpoints included change in plasma insulin, glucagon, CCK, total plasma bile acid concentrations, plasma concentrations of Ex9-39 (on the 2 days of infusion of Ex9-39), and serum acetaminophen (for evaluation of gastric emptying). Furthermore, gallbladder volume, appetite, and ad libitum lunch intake were evaluated.

Eligibility criteria. Prior to the experiments, patients were screened according to inclusion and exclusion criteria, including family history, physical examination, standard blood panel, and urine for albumin and creatinine. Inclusion criteria included White race, BMI $>25 \mathrm{~kg} / \mathrm{m}^{2}$, older than 18 years of age, normal hemoglobin, normal thyroid function (thyroid-stimulatory hormone within normal range), and informed consent. 
Exclusion criteria included a history of abdominal surgery, gastrointestinal disorders including gallstone disease, nephropathy (creatinine $>130 \mu \mathrm{mol} / 1$ and/or albuminuria), liver disease (alanine aminotransferase and/or aspartate aminotransferase $\geq 2$ times normal serum upper limit) and treatment with DPP-4 inhibitors, GLP-1 receptor agonists and/or insulin, and treatment with medicine that could not be paused for 12 hours.

Experimental procedures. The patients were studied on 4 separate experimental days separated by at least 48 hours. On all 4 days, the patients were studied in recumbent position after a 10-hour overnight fast including liquids, medication, and tobacco use. The patients were instructed not to take their antidiabetic medication for 1 week prior to each experimental day and to refrain from exercise on experiment days and the day before. After arriving at the lab, an i.v. catheter was inserted into a cubital vein in each arm ( 1 for blood sampling and 1 for infusion). The forearm used for blood sampling was wrapped in a heating pad $\left(50^{\circ} \mathrm{C}\right)$ for arterialization of venous blood during the experiment. Continuous isovolemic infusions of either saline or Ex9-39 were then started at a rate of $10 \mathrm{ml} /$ hour by the use of a pump (Terufusion Infusion Pump, TE-171, Terumo), for Ex9-39 corresponding to a rate of $450 \mathrm{pmol} \times \mathrm{kg}_{\text {body weight }}{ }^{-1} \times \mathrm{min}^{-1}$, since this dose has previously been shown to block the insulinotropic effect of synthetic GLP-1 by 90\% (64). After 30 minutes, at time 0 minutes, the patients ingested a $200 \mathrm{ml}, 1,264 \mathrm{~kJ}$ (302 kcal) mixed liquid meal (chocolate-flavored Nutridrink, $36.8 \mathrm{~g}$ carbohydrates, $12.0 \mathrm{~g}$ protein and $11.6 \mathrm{~g}$ fat; Nutricia) mixed with a dispersion of $1,500 \mathrm{mg}$ of acetaminophen in $100 \mathrm{ml}$ of water (for evaluation of gastric emptying) and metformin 1,500 mg or placebo. The dispersions were mixed for 20 minutes at room temperature before intake. The patients were instructed to ingest the $300 \mathrm{ml}$ of liquid over 5-10 minutes. Three baseline blood samples were drawn immediately before ingestion of the liquid meal, and further samples were drawn at specific time points from $0-240$ minutes. The study also included 2 days of colesevelam + saline and colesevelam + placebo, which will be discussed in future work.

Data collection. For analyses of GLP-1, glucagon, and Ex9-39, blood was sampled into chilled tubes containing EDTA and a specific DPP-4 inhibitor ( $3 \mathrm{mmol} / 1$ valine-pyrrolidide, $10 \mu 1 / \mathrm{ml}$ blood, a gift from Novo Nordisk) and kept on ice until centrifugation. For analysis of insulin, C-peptide, CCK, and total bile acids, blood was collected in dry tubes for coagulation (15 minutes at room temperature). For analysis of acetaminophen, blood was collected in tubes containing heparin. All samples were centrifuged for 20 minute at $1,200 \mathrm{~g}$ and $4^{\circ} \mathrm{C}$. Plasma samples for GLP-1, glucagon, Ex9-39, CCK, and total bile acids were stored at $-20^{\circ} \mathrm{C}$, and plasma samples for insulin, C-peptide, and acetaminophen were stored at $-80^{\circ} \mathrm{C}$. For measurement of plasma glucose, blood was sampled into fluoride tubes and centrifuged immediately at 7,400 $\mathrm{g}$ for 2 minutes at room temperature and analyzed bedside. Gallbladder size was evaluated by ultrasound imaging (LOGIQ E9, GE Healthcare) at 6 specific time points (baseline was based on the average of 2 sequential measurements) during the experiment. The gallbladder was measured in 3 dimensions (length and 2 cross-sectional measurements) by a single investigator $(\mathrm{MH})$. Gastric emptying was determined from acetaminophen absorption (65). Gastric emptying is the rate-limiting step for the appearance of orally administered acetaminophen in the blood, and serum acetaminophen time-to-peak and $\mathrm{AUC}_{60 \text { min }}$ indicate gastric emptying velocity (65). At 6 time points during the experiment, using standardized visual analog scales (VAS), the patients evaluated hunger, satiety, fullness, prospective food consumption, general well-being, nausea, and thirst (66). Before leaving the lab, the patients were served a standardized ad libitum meal and instructed to eat until pleasantly satiated, after which total food intake was noted (66).

Materials. Metformin (Metformin Actavis tablets containing $500 \mathrm{mg}$ of metformin, Actavis A/S) and acetaminophen (Panodil powder containing $500 \mathrm{mg}$ of acetaminophen, GlaxoSmithKline A/S) were purchased from the Pharmacy of the Capital Region of Denmark. Ex9-39 was purchased from Bachem AG. Ex9-39 was dissolved in sterilized water with 1\% human albumin (Plasma Product Unit PSU, Novo Nordisk A/S ) and subjected to sterile filtration. Ex9-39 was stored frozen $\left(-20^{\circ} \mathrm{C}\right)$ under sterile conditions until the day of the experiment. Ex9-39 was demonstrated to be $99.5 \%$ pure by high-performance liquid chromatography. Ex9-39 from the same batch was used for all experimental days.

Laboratory analyzes. Plasma glucose was measured on a glucose analyzer using the glucose oxidase method (Yellow Springs Instrument model 2300 STAT plus analyzer; YSI Inc.). Plasma insulin and C-peptide were measured using a 2-sided electrochemiluminescence immunoassay (Roche/Hitachi Modular analytics; Roche Diagnostic GmbH) (18). Plasma concentrations of total GLP-1 and CCK were measured by radioimmunoassays as previously described $(67,68)$. Glucagon was measured with the LINCO assay (MilliporeSigma) because this assay does not cross-react with Ex9-39 (69). Ex9-39 was measured using 
Table 3. Characteristics of the specimen donors

\begin{tabular}{lcc}
\hline & Colon specimen & lleum specimen \\
$\mathbf{n}$ & 46 & 10 \\
Age (years) & $67 \pm 13(38-87)$ & $70 \pm 10(52-83)$ \\
Sex (male/female) & $25 / 21$ & $3 / 7$ \\
BMI (kg/m²) & $29.3 \pm 6.7(19-55)$ & $31.6 \pm 6.3(25-45)$ \\
Have type 2 diabetes (yes/no) & $11 / 35$ & $3 / 7$ \\
Metformin-treated (yes/no) & $6 / 40$ & $2 / 8$ \\
Data are means \pm SEM, with range in parentheses. & & \\
\hline
\end{tabular}

antibody 3145 raised in rabbits immunized with exendin-4, which shows 100\% cross-reactivity with Ex9-39 but only $0.01 \%$ cross-reactivity with GLP-1, glucagon, and GIP (69). Serum acetaminophen was measured by the Vitros ACET slide, as previously described (70).

Human tissue collection for ex vivo studies in human ileal and colonic mucosae. Human ileal and colonic tissue was obtained from patients undergoing bowel resection for cancer or stoma reversal. In the case of resection specimens, samples were obtained from sites at least 10 centimeters away from the tumor location. Specimens from patients that were indicated for any form of inflammatory bowel disease were excluded from this study. Characteristics of the patient cohort are listed in Table 3. The specimens were immediately placed in ice-cold Krebs buffer $\left(\mathrm{NaCl} 138 \mathrm{mM}, \mathrm{KCl} 4.5 \mathrm{mM}, \mathrm{CaCl}_{2} 2.6 \mathrm{mM}, \mathrm{NaHCO}_{3} 4.2 \mathrm{mM}, \mathrm{MgCl}_{2} 1.2\right.$ $\mathrm{mM}, \mathrm{NaH}_{2} \mathrm{PO}_{4} 1.2 \mathrm{mM}$, HEPES $10 \mathrm{mM}$, Glucose $5 \mathrm{mM}$; MilliporeSigma) and transported to the laboratory for dissection within 15 minutes. The specimens were rinsed with ice-cold Krebs buffer to remove any luminal content and dissected clear of adipose, muscular, and connective tissues. The mucosae were gently dissected off from the submucosae as intact sheets using a stainless-steel spatula, cut into 5-mm pieces, and weighed individually. The mucosal pieces were then transferred to a 96-well plate for secretion assays.

Secretion experiments. Mucosal pieces were incubated with $250 \mu 1$ of buffer (control) or buffer containing test agents in a 96-well plate for 15 minutes as previous (71). While the tissue remains viable for up to 2 hours and displays secretory responses to various ligands within this time frame (unpublished observations), we find that this 15 -minute time point provides the greatest degree of fidelity for most reagents tested. The buffer was a modified Krebs buffer described above with the addition of sitagliptin $1 \mu \mathrm{M}, 0.1 \%$ fatty acid-free BSA (A1595, MilliporeSigma) at $\mathrm{pH}$ 7.4. Following incubation at $37^{\circ} \mathrm{C}$ in $95 \% \mathrm{O}_{2} / 5 \% \mathrm{CO}_{2}$, supernatants were collected and stored in aliquots at $-20^{\circ} \mathrm{C}$. Active GLP-1 levels were quantitated using commercially available ELISA kits, according to manufacturer's instructions (EGLP-35K, MilliporeSigma).

Test agents. IBMX and FSK (I5879 and F6886, MilliporeSigma) (10 $\mu \mathrm{M}$ each) and $70 \mathrm{mM} \mathrm{KCl}$ were used as positive controls. For the $70-\mathrm{mM} \mathrm{KCl}$ solution, an equimolar amount of $\mathrm{NaCl}$ was removed to maintain osmolarity. The following compounds were purchased from MilliporeSigma: Metformin (PHR1084), Lopinavir (SML1222), Quinine hydrochloride dehydrate (Q1125), and Fluoxetine (F132). The AMPK inhibitor, dorsomorphin, was from MilliporeSigma (171260), as well. Only samples that show positive response to at least 1 positive control ( $70 \mathrm{mM} \mathrm{KCl}$ or $10 \mu \mathrm{M}$ IBMX/FSK) were included in analysis.

Statistics. Results are reported as means \pm SEM unless otherwise stated. ISR was modeled by application of population-based parameters for C-peptide kinetics to the measured C-peptide concentrations (the deconvolution method) (72). ISR is expressed as picomoles insulin secreted per minute per kilogram body weight. The increased plasma glucose associated with Ex9-39 infusion is, in itself, a driver of insulin secretion. Accordingly, insulin, C-peptide, and ISR data are reported as ratios of the glucose concentration. AUC values were calculated using the trapezoidal rule. If not otherwise stated, AUC values are presented as iAUCs (calculated by subtracting the mean baseline value multiplied by 180 minutes from the total AUC from 0-180 minutes). Gallbladder volume was calculated using the ellipse formula, and gallbladder ejection fraction was calculated as the difference between baseline and the lowest volume divided by the baseline value. Paired, 2-tailed Student's $t$ tests were used for comparison of the effect of Ex9-39 and saline at baseline, regardless of treatment. One-way repeated measures ANOVA and post hoc Tukey's multiple comparisons test was used to test for variations and differences of the basal values, AUC, and iAUC between interventions. Two-way ANOVA was performed to illustrate the individual effect of metformin and Ex9-39 on postprandial glucose excursions, as well as a potential interaction 
between the 2 factors (metformin and Ex9-39). For the ex vivo study, a paired 1-way ANOVA with Fisher's least significant difference post-hoc test was used for multiple comparisons, and a paired Student's $t$ tests was used for single comparisons. In case of nonnormally distributed data, logarithmic transformation was performed before statistical testing. All tests were 2-sided, and differences resulting in $P<0.05$ were considered significant. Statistical analyzes were carried out using SAS/STAT software version 12.3 (SAS Institute Inc.) or GraphPad Prism software version 6.03 (GraphPad Software Inc.).

Study approval. The clinical study was performed in accordance with the principles of the Declaration of Helsinki II. All patients provided written informed consent prior to any study activity. For the ex vivo study, patients gave written informed consent for ileum and colon tissue donation from resected small and large intestine at Flinders Medical Centre and Flinders Private Hospital approved by the Southern Adelaide Clinical Human Research Ethics Committee.

\section{Author contributions}

MH, DPS, UR, and FKK designed the clinical study, while EWLS and DJK designed the ex vivo study. Recruitment of patients for the clinical study was performed by $\mathrm{MH}$, TV, and FKK, while recruitment of patients for the ex vivo study was performed by DAW, DDF, PR, PH, LS, and SD. The clinical experiments were performed by $\mathrm{MH}$ and $\mathrm{EB}$ at Center for Diabetes Research at Gentofte Hospital, University of Copenhagen. MH, DPS, and JSH performed statistical analyses. MH, DPS, JSH, JJH, and FKK interpreted the clinical data. JJH was responsible for measures of plasma concentrations of GLP-1 and glucagon. JFR was responsible for measures of plasma concentrations CCK. The ex vivo studies were carried out by EWLS. MH, DJK, and EWLS drafted the manuscript. The manuscript was edited by MH, EB, DPS, JSH, UR, JFR, TV, JJH, DJK, EWLS, RLY, APL, MLJ, DAW, and FKK. All authors have approved the final version of the manuscript. FKK conceived the clinical study, is the guarantor of this work, and, as such, had access to all study data and takes responsibility for the integrity of the data and the data analysis. EWLS and DJK conceived the ex vivo study, and DJK is the guarantor of this work and, as such, had access to all study data and takes responsibility for the integrity of the data and the data analysis.

\section{Acknowledgments}

The authors are grateful to the voluntary patients who made this work possible. The authors thank S. Schmidt, A. Hansen, S. Pilgaard Olesen, L. Albak, L. Jespersen, J. Jagtboe, and R. Kröncke for their expert technical assistance. The study was supported by unrestricted grants from A.P. Møller Fonden, the Novo Nordisk Foundation, and The Danish Medical Association Research Grant. The Novo Nordisk Foundation Center for Basic Metabolic Research is an independent research center at the University of Copenhagen, partially funded by an unrestricted grant from the Novo Nordisk Foundation. TV has received lecture fees from, consulted for, and/or is an Advisory Board member of AstraZeneca, Boehringer Ingelheim Pharmaceuticals, Bristol-Myers Squibb, Eli Lilly and Company, GI dynamics, Merck Sharp \& Dohme, Novo Nordisk, Novartis, Sanofi, Takeda, and Zealand Pharma. FKK has received lecture fees from, consulted for, and/or is an Advisory Board member of AstraZeneca, Boehringer Ingelheim Pharmaceuticals, Eli Lilly and Company, Gilead Sciences, Merck Sharp \& Dohme, Novo Nordisk, Ono Pharmaceuticals, Sanofi, and Zealand Pharma. DJK and RLY acknowledge funding from the Australian Research Council (LP150100419) and the National Health and Medical Research Council (APP1088737, APP1081182). Funding was received by RLY and DJK from Pfizer Inc. through an Emerging Science Grant.

Address correspondence to: Filip K. Knop, Clinical Metabolic Physiology, Steno Diabetes Center Copenhagen, Gentofte Hospital, Kildegårdsvej 28, DK-2900 Hellerup, Denmark. Phone: 45.3867.4266; Email: filipknop@dadlnet.dk. Or to: Damien J. Keating, Flinders University of South Australia and South Australian Health and Medical Research Institute, Adelaide, Australia. Phone: 61.882044282; Email: damien.keating@flinders.edu.au.

MH and JSH's present address are: Novo Nordisk A/S, Bagsværd, Denmark. 
1. McCreight LJ, Bailey CJ, Pearson ER. Metformin and the gastrointestinal tract. Diabetologia. 2016;59(3):426-435.

2. Miller RA, Chu Q, Xie J, Foretz M, Viollet B, Birnbaum MJ. Biguanides suppress hepatic glucagon signalling by decreasing production of cyclic AMP. Nature. 2013;494(7436):256-260

3. Chacra AR. Evolving metformin treatment strategies in type-2 diabetes: from immediate-release metformin monotherapy to extended-release combination therapy. Am J Ther. 2014;21(3):198-210.

4. Zhou G, et al. Role of AMP-activated protein kinase in mechanism of metformin action. J Clin Invest. 2001;108(8):1167-1174.

5. Fisher JS, Gao J, Han DH, Holloszy JO, Nolte LA. Activation of AMP kinase enhances sensitivity of muscle glucose transport to insulin. Am J Physiol Endocrinol Metab. 2002;282(1):E18-E23.

6. Grisouard J, et al. Mechanisms of metformin action on glucose transport and metabolism in human adipocytes. Biochem Pharmacol. 2010;80(11):1736-1745.

7. Burcelin R. The antidiabetic gutsy role of metformin uncovered? Gut. 2014;63(5):706-707.

8. Sum CF, Webster JM, Johnson AB, Catalano C, Cooper BG, Taylor R. The effect of intravenous metformin on glucose metabolism during hyperglycaemia in type 2 diabetes. Diabet Med. 1992;9(1):61-65.

9. Hundal RS, et al. Mechanism by which metformin reduces glucose production in type 2 diabetes. Diabetes. 2000;49(12):20632069.

10. Schwartz S, Fonseca V, Berner B, Cramer M, Chiang YK, Lewin A. Efficacy, tolerability, and safety of a novel once-daily extended-release metformin in patients with type 2 diabetes. Diabetes Care. 2006;29(4):759-764.

11. DeFronzo RA, et al. Once-daily delayed-release metformin lowers plasma glucose and enhances fasting and postprandial GLP-1 and PYY: results from two randomised trials. Diabetologia. 2016;59(8):1645-1654.

12. Buse JB, et al. The Primary Glucose-Lowering Effect of Metformin Resides in the Gut, Not the Circulation: Results From Short-term Pharmacokinetic and 12-Week Dose-Ranging Studies. Diabetes Care. 2016;39(2):198-205.

13. Mannucci E, et al. Effects of metformin on glucagon-like peptide-1 levels in obese patients with and without Type 2 diabetes. Diabetes Nutr Metab. 2004;17(6):336-342.

14. Migoya EM, et al. Dipeptidyl peptidase-4 inhibitors administered in combination with metformin result in an additive increase in the plasma concentration of active GLP-1. Clin Pharmacol Ther. 2010;88(6):801-808.

15. Thondam SK, Cross A, Cuthbertson DJ, Wilding JP, Daousi C. Effects of chronic treatment with metformin on dipeptidyl peptidase-4 activity, glucagon-like peptide 1 and ghrelin in obese patients with Type 2 diabetes mellitus. Diabet Med. 2012;29(8):e205-e210.

16. Wu T, Thazhath SS, Bound MJ, Jones KL, Horowitz M, Rayner CK. Mechanism of increase in plasma intact GLP-1 by metformin in type 2 diabetes: stimulation of GLP-1 secretion or reduction in plasma DPP-4 activity? Diabetes Res Clin Pract. 2014;106(1):e3-e6.

17. Jorsal $\mathrm{T}$, et al. Altered enteroendocrine expression of glucagon and somatostatin in the gut of patients with type 2 diabetes compared with healthy matched controls. Diabetologia. 2014;57.

18. Holst JJ. The physiology of glucagon-like peptide 1. Physiol Rev. 2007;87(4):1409-1439.

19. Mulherin AJ, Oh AH, Kim H, Grieco A, Lauffer LM, Brubaker PL. Mechanisms underlying metformin-induced secretion of glucagon-like peptide-1 from the intestinal L cell. Endocrinology. 2011;152(12):4610-4619.

20. Maida A, Lamont BJ, Cao X, Drucker DJ. Metformin regulates the incretin receptor axis via a pathway dependent on peroxisome proliferator-activated receptor- $\alpha$ in mice. Diabetologia. 2011;54(2):339-349.

21. Kappe C, Patrone C, Holst JJ, Zhang Q, Sjöholm A. Metformin protects against lipoapoptosis and enhances GLP-1 secretion from GLP-1-producing cells. J Gastroenterol. 2013;48(3):322-332.

22. Scarpello JH, Hodgson E, Howlett HC. Effect of metformin on bile salt circulation and intestinal motility in type 2 diabetes mellitus. Diabet Med. 1998;15(8):651-656.

23. Parks DJ, et al. Bile acids: natural ligands for an orphan nuclear receptor. Science. 1999;284(5418):1365-1368.

24. Fang S, et al. Intestinal FXR agonism promotes adipose tissue browning and reduces obesity and insulin resistance. Nat Med. 2015;21(2):159-165.

25. Maruyama T, et al. Identification of membrane-type receptor for bile acids (M-BAR). Biochem Biophys Res Commun. 2002;298(5):714-719.

26. Watanabe $\mathrm{M}$, et al. Bile acids induce energy expenditure by promoting intracellular thyroid hormone activation. Nature. 2006;439(7075):484-489.

27. Thomas C, et al. TGR5-mediated bile acid sensing controls glucose homeostasis. Cell Metab. 2009;10(3):167-177.

28. Ma K, Saha PK, Chan L, Moore DD. Farnesoid X receptor is essential for normal glucose homeostasis. J Clin Invest. 2006;116(4):1102-1109.

29. Hansen M, et al. Effect of chenodeoxycholic acid and the bile acid sequestrant colesevelam on glucagon-like peptide-1 secretion. Diabetes Obes Metab. 2016;18(6):571-580.

30. Wu T, et al. Effects of rectal administration of taurocholic acid on glucagon-like peptide-1 and peptide YY secretion in healthy humans. Diabetes Obes Metab. 2013;15(5):474-477.

31. Adrian TE, et al. Deoxycholate is an important releaser of peptide YY and enteroglucagon from the human colon. Gut. 1993;34(9):1219-1224

32. Schirra J, Sturm K, Leicht P, Arnold R, Göke B, Katschinski M. Exendin(9-39)amide is an antagonist of glucagon-like peptide-1(7-36)amide in humans. J Clin Invest. 1998;101(7):1421-1430.

33. Deacon CF, Wamberg S, Bie P, Hughes TE, Holst JJ. Preservation of active incretin hormones by inhibition of dipeptidyl peptidase IV suppresses meal-induced incretin secretion in dogs. J Endocrinol. 2002;172(2):355-362.

34. Toft-Nielsen MB, Madsbad S, Holst JJ. Continuous subcutaneous infusion of glucagon-like peptide 1 lowers plasma glucose and reduces appetite in type 2 diabetic patients. Diabetes Care. 1999;22(7):1137-1143.

35. Bahne E, Hansen M, Brønden A, Sonne DP, Vilsbøll T, Knop FK. Involvement of glucagon-like peptide-1 in the glucose-lowering effect of metformin. Diabetes Obes Metab. 2016;18(10):955-961.

36. Sonne DP, Rehfeld JF, Holst JJ, Vilsbøll T, Knop FK. Postprandial gallbladder emptying in patients with type 2 diabetes: potential implications for bile-induced secretion of glucagon-like peptide 1. Eur J Endocrinol. 2014;171(4):407-419.

37. Vardarli I, Arndt E, Deacon CF, Holst JJ, Nauck MA. Effects of sitagliptin and metformin treatment on incretin hormone and 
insulin secretory responses to oral and "isoglycemic" intravenous glucose. Diabetes. 2014;63(2):663-674.

38. Tsilchorozidou T, Batterham RL, Conway GS. Metformin increases fasting plasma peptide tyrosine tyrosine (PYY) in women with polycystic ovarian syndrome (PCOS). Clin Endocrinol (Oxf). 2008;69(6):936-942.

39. Napolitano A, et al. Novel gut-based pharmacology of metformin in patients with type 2 diabetes mellitus. PLoS One. 2014;9(7):e100778.

40. Pernicova I, Korbonits M. Metformin--mode of action and clinical implications for diabetes and cancer. Nat Rev Endocrinol. 2014;10(3):143-156

41. Shu Y, et al. Effect of genetic variation in the organic cation transporter 1 (OCT1) on metformin action. J Clin Invest. 2007;117(5):1422-1431.

42. Becker ML, Visser LE, van Schaik RH, Hofman A, Uitterlinden AG, Stricker BH. Interaction between polymorphisms in the OCT1 and MATE1 transporter and metformin response. Pharmacogenet Genomics. 2010;20(1):38-44.

43. Dujic T, Zhou K, Tavendale R, Palmer CN, Pearson ER. Effect of Serotonin Transporter 5-HTTLPR Polymorphism on Gastrointestinal Intolerance to Metformin: A GoDARTS Study. Diabetes Care. 2016;39(11):1896-1901.

44. Raghupathi R, et al. Identification of unique release kinetics of serotonin from guinea-pig and human enterochromaffin cells. J Physiol (Lond). 2013;591(23):5959-5975.

45. Keating DJ, Spencer NJ. Release of 5-hydroxytryptamine from the mucosa is not required for the generation or propagation of colonic migrating motor complexes. Gastroenterology. 2010;138(2):659-70 670.e1.

46. Graham GG, et al. Clinical pharmacokinetics of metformin. Clin Pharmacokinet. 2011;50(2):81-98.

47. Manning S, Batterham RL. The role of gut hormone peptide YY in energy and glucose homeostasis: twelve years on. Annu Rev Physiol. 2014;76:585-608.

48. Nauck MA, Meier JJ. The incretin effect in healthy individuals and those with type 2 diabetes: physiology, pathophysiology, and response to therapeutic interventions. Lancet Diabetes Endocrinol. 2016;4(6):525-536.

49. Hare KJ, et al. Preserved inhibitory potency of GLP-1 on glucagon secretion in type 2 diabetes mellitus. J Clin Endocrinol Metab. 2009;94(12):4679-4687.

50. Kjems LL, Holst JJ, Vølund A, Madsbad S. The influence of GLP-1 on glucose-stimulated insulin secretion: effects on beta-cell sensitivity in type 2 and nondiabetic subjects. Diabetes. 2003;52(2):380-386.

51. Nicolaus M, Brödl J, Linke R, Woerle HJ, Göke B, Schirra J. Endogenous GLP-1 regulates postprandial glycemia in humans: relative contributions of insulin, glucagon, and gastric emptying. J Clin Endocrinol Metab. 2011;96(1):229-236.

52. Hare KJ, Vilsbøll T, Asmar M, Deacon CF, Knop FK, Holst JJ. The glucagonostatic and insulinotropic effects of glucagon-like peptide 1 contribute equally to its glucose-lowering action. Diabetes. 2010;59(7):1765-1770.

53. DeFronzo RA, Barzilai N, Simonson DC. Mechanism of metformin action in obese and lean noninsulin-dependent diabetic subjects. J Clin Endocrinol Metab. 1991;73(6):1294-1301

54. Gelling RW, et al. Lower blood glucose, hyperglucagonemia, and pancreatic alpha cell hyperplasia in glucagon receptor knockout mice. Proc Natl Acad Sci USA. 2003;100(3):1438-1443.

55. Lund A, et al. Evidence of Extrapancreatic Glucagon Secretion in Man. Diabetes. 2016;65(3):585-597.

56. Meier JJ, et al. Normalization of glucose concentrations and deceleration of gastric emptying after solid meals during intravenous glucagon-like peptide 1 in patients with type 2 diabetes. J Clin Endocrinol Metab. 2003;88(6):2719-2725.

57. Deane AM, et al. Endogenous glucagon-like peptide-1 slows gastric emptying in healthy subjects, attenuating postprandial glycemia. J Clin Endocrinol Metab. 2010;95(1):215-221.

58. Schvarcz E, Palmér M, Aman J, Horowitz M, Stridsberg M, Berne C. Physiological hyperglycemia slows gastric emptying in normal subjects and patients with insulin-dependent diabetes mellitus. Gastroenterology. 1997;113(1):60-66.

59. Gielkens HA, van Oostayen JA, Frölich M, Biemond I, Lamers CB, Masclee AA. Dose-dependent inhibition of postprandial gallbladder motility and plasma hormone secretion during acute hyperglycemia. Scand J Gastroenterol. 1998;33(10):1074-1079.

60. Keller J, et al. Effect of exenatide on cholecystokinin-induced gallbladder emptying in fasting healthy subjects. Regul Pept. 2012;179(1-3):77-83.

61. Marzio L, et al. Relationship between gastric and gallbladder emptying and refilling in normal subjects and patients with $\mathrm{H}$. pylori-positive and -negative idiopathic dyspepsia and correlation with symptoms. Dig Dis Sci. 1996;41(1):26-31.

62. Steinert RE, et al. Effect of glucagon-like peptide-1 receptor antagonism on appetite and food intake in healthy men. Am J Clin Nutr. 2014;100(2):514-523.

63. Geary N, Kissileff HR, Pi-Sunyer FX, Hinton V. Individual, but not simultaneous, glucagon and cholecystokinin infusions inhibit feeding in men. Am J Physiol. 1992;262(6 Pt 2):R975-R980.

64. Schirra J, Göke B. GLP-1--a candidate humoral mediator for glucose control after Roux-en-Y gastric bypass. Diabetes. 2014;63(2):387-389.

65. Medhus AW, Lofthus CM, Bredesen J, Husebye E. Gastric emptying: the validity of the paracetamol absorption test adjusted for individual pharmacokinetics. Neurogastroenterol Motil. 2001;13(3):179-185.

66. Flint A, Raben A, Blundell JE, Astrup A. Reproducibility, power and validity of visual analogue scales in assessment of appetite sensations in single test meal studies. Int J Obes Relat Metab Disord. 2000;24(1):38-48.

67. Krarup T, Holst JJ. The heterogeneity of gastric inhibitory polypeptide in porcine and human gastrointestinal mucosa evaluated with five different antisera. Regul Pept. 1984;9(1-2):35-46.

68. Rehfeld JF. Accurate measurement of cholecystokinin in plasma. Clin Chem. 1998;44(5):991-1001.

69. Kielgast U, Holst JJ, Madsbad S. Antidiabetic actions of endogenous and exogenous GLP-1 in type 1 diabetic patients with and without residual $\beta$-cell function. Diabetes. 2011;60(5):1599-1607.

70. Miceli JN, Aravind MK, Cohen SN, Done AK. Simultaneous measurements of acetaminophen and salicylate in plasma by liquid chromatography. Clin Chem. 1979;25(6):1002-1004.

71. Sun EW, et al. Mechanisms Controlling Glucose-Induced GLP-1 Secretion in Human Small Intestine. Diabetes. 2017;66(8):2144-2149.

72. Van Cauter E, Mestrez F, Sturis J, Polonsky KS. Estimation of insulin secretion rates from C-peptide levels. Comparison of individual and standard kinetic parameters for C-peptide clearance. Diabetes. 1992;41(3):368-377. 